See discussions, stats, and author profiles for this publication at: https://www.researchgate.net/publication/325112154

The domain of knowledge organization: A bibliometric analysis of prolific authors and their intellectual space

Article in Knowledge Organization · January 2018

DOI: 10.5771/0943-7444-2018-1-13

2 authors, including:

Renata Cristina Gutierres Castanha

São Paulo State University

21 PUBLICATIONS 21 CITATIONS

SEE PROFILE 


\title{
The Domain of Knowledge Organization: A Bibliometric Analysis of Prolific Authors and Their Intellectual Space
}

\author{
Renata Cristina Gutierres Castanha* and Dietmar Wolfram** \\ *Universidade Estadual Paulista (UNESP/Marilia), \\ 737 Hygino Muzzi Filho Avenue, 17525-900 Marilia, Brazil, \\ <regutierres@gmail.com> \\ **University of Wisconsin-Milwaukee, School of Information Studies, \\ P.O. Box 413, Milwaukee, WI 53201, USA, \\ <dwolfram@uwm.edu>
}

\begin{abstract}
Renata Cristina Gutierres Castanha is a PhD candidate in information science at the Universidade Estadual Paulista (UNESP / Marilia) in Brazil. She has a master's degree in information science and a bachelor's degree in mathematics. Her research interests include knowledge organization, scientometrics, graduate assessment, academic genealogy and topological indicators. Ms. Castanha is member of the International Society for Knowledge Organization (ISKO).

Dietmar Wolfram is a professor at the School of Information Studies at the University of WisconsinMilwaukee. He received his PhD in library and information science from the University of Western Ontario. His primary research interests include scholarly communication, applied informetrics, information retrieval (IR) and the intersection of IR and informetrics. He currently serves as President of the Association for Library and Information Science Education.
\end{abstract}

Castanha, Renata Cristina Gutierres and Dietmar Wolfram. 2018. "The Domain of Knowledge Organization: A Bibliometric Analysis of Prolific Authors and Their Intellectual Space." Knowledge Organization 45(1): 13-22. 26 references. DOI:10.5771/0943-7444-2018-1-13.

\begin{abstract}
The domain of knowledge organization (KO) represents a foundational area of information science. One way to better understand the intellectual structure of the $\mathrm{KO}$ domain is to apply bibliometric methods to key contributors to the literature. This study analyzes the most prolific contributing authors to the journal Knowledge Organization, the sources they cite and the citations they receive for the period 1993 to 2016. The analyses were conducted using visualization outcomes of citation, co-citation and author bibliographic coupling analysis to reveal theoretical points of reference among authors and the most prominent research themes that constitute this scientific community. Birger Hjørland was the most cited author, and was situated at or near the middle of each of the maps based on different citation relationships. The proximities between authors resulting from the different citation relationships demonstrate how authors situate themselves intellectually through the citations they give and how other authors situate them through the citations received. There is a consistent core of theoretical references as well among the most productive authors. We observed a close network of scholarly communication between the authors cited in this core, which indicates the actual role of the journal Knowledge Organization as a space for knowledge construction in the area of knowledge organization.
\end{abstract}

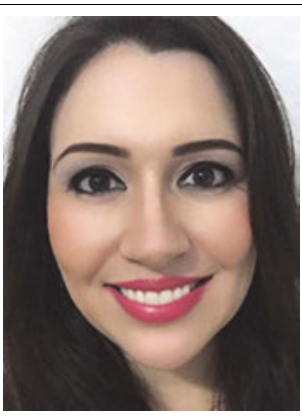

Received: 12 July 2017; Revised: 28 August 2017; Accepted 1 September 2017

Keywords: authors, knowledge organization, domain analysis, citation, research, scientific communication

\subsection{Introduction}

Within the context of information science, knowledge organization (KO) according to Guimarães (2008), stands as a core mediator between the production and use of information, configuring a set of processes that establishes the mediation between knowledge, that once produced, is embodied and socialized in such a manner that it can serve as a foundation for the following generation of new knowledge, characterizing what can be called as a spiral flow of information.

Furthermore, Hjørland and Albrechtsen (1995) claim that the best way to understand information within information science itself is to study the knowledge do- 
mains of the discourse communities in which analogous theories of thought, language and knowledge are highlighted. In that context, research, through its scientific production, is a fundamental driving force of information and knowledge development, given that the publication is intrinsic to research.

Therefore, scientific knowledge construction results from a process involving individuals' social and work relationships in a discourse community, and in this context, it is constructed and disseminated through records (i.e., publications). This practice has been the core study of $\mathrm{KO}$ under the aegis of information science. Guimarães (2015) claims the area of knowledge organization is still in a continuous construction phase, seeking the construction and boundaries of its own conceptual foundation and its limits, due to its different theoretical influences.

That said, and considering the importance of identifying and studying the science dynamics of $\mathrm{KO}$ in the context of information science, this study aims to analyze the most productive authors contributing to the journal Knowledge Organization over the period 1993-2016, along with the authors' references and citations received. More specifically, this study performs a citation, co-citation and bibliographic coupling analysis of the KO journal literature in order to verify the dynamics of the $\mathrm{KO}$ area using these indicators (i.e., measures that describe the state or degree of an entity of interest). We also analyze the theoretical references and most useful themes that have constituted this scholarly community.

\subsection{Knowledge Organization, Domain Analysis and Bibliometrics}

The domain of knowledge organization is in continuous development. It is also a relatively autonomous, interdisciplinary space. It interfaces with other subject areas and is concerned with issues of a theoretical and methodological nature that contribute to the systematization, production, organization, dissemination, representation and retrieval of information in different scholarly contexts.

Our lack of understanding about the way knowledge organization research is guided points to the need to build a critical and multidimensional analysis to understand the component aspects of research on this topic. Whereas research in knowledge organization, as well as in all other scientific areas, result in a dynamic context of production and elaboration of knowledge, this context is continuously transformed because of its practical application and scientific communication.

Knowledge organization contributes to the dynamics of other areas that rely on information and knowledge, crucial elements for endless construction and review of scientific knowledge. This demand, accentuated by in- creasing branching and the interrelatedness of knowledge, requires more complex processes for the study of its objects, because research activities are determined by both the social and historical context as the theoretical and methodological frameworks guiding concepts and scientific assumptions, according to Arboit et al. (2015).

For Smiraglia (2013), knowledge organization is devoted to the conceptual order of knowledge, and it is the research community devoted to classification and ontology, thesauri and controlled vocabulary, epistemology and warrant, as well as the development of applied systems for all of the aforementioned areas. Furthermore, for the author, there is a long tradition of the activities and tools of $\mathrm{KO}$ : classification, taxonomy and typology. Specific applications for information storage and retrieval such as indexes, bibliographic classifications, etc., have been part of the practice of librarianship since the late nineteenth century. The formal knowledge organization domain, represented by the International Society for Knowledge Organization (ISKO) and its chapters, councils and publications, dates from 1989.

Ongoing discussions in the knowledge organization literature include the interdisciplinary characteristic of the area, which results in fuzzy boundaries between domains. Extrapolating its own ISKO domain, currently studying its domain has been the focus of several studies that propose to define and conceptualize its scope, its object of study, its theoretical foundations and mainly outline methodologies that can best understand the constructed knowledge.

According to Hjørland (2008), there are different historical and theoretical approaches to and theories about $\mathrm{KO}$, which are related to different views of knowledge, cognition, language and social organization. For the author, $\mathrm{KO}$ as a field of study is concerned with the nature and quality of such knowledge organizing processes (KOP) as well as the knowledge organizing systems (KOS) used to organize documents, document representations, works and concepts. Library and information science (LIS) is the central discipline of $\mathrm{KO}$ in this narrow sense, although seriously challenged by, among other fields, computer science.

The central discipline concerned with $\mathrm{KO}$ in the narrow sense of the word is LIS, and other disciplines such as the sociology of knowledge, the single sciences and metaphysics are central disciplines concerned with $\mathrm{KO}$ in the broader sense of the word. The importance of regarding the broader field of $\mathrm{KO}$ is related to the question about how $\mathrm{KO}$ in the narrow sense can be developed. A central claim of this paper is that $\mathrm{KO}$ in the narrow sense cannot develop a fruitful body of knowledge without considering $\mathrm{KO}$ in the broader perspective. In other words, as Hjørland (2008) espouses, there exists no closed "universe of knowledge" that can be studied by $\mathrm{KO}$ in isolation from all the other sciences' study of reality. 
$\mathrm{KO}$ is not just something the LIS-profession can do without considering research in other domains, for example, computer science, linguistics, theory of knowledge, etc. For Hjørland (2008), an understanding of the nature of knowledge, cognition, language and social organization is decisive for the understanding of $\mathrm{KO}$ and thus for the ability to design, evaluate and use knowledge organizing processes and knowledge organizing systems. Other fields may have an interest in the defining questions of knowledge organization or may be considered related disciplines. Especially in knowledge organization, Smiraglia (2011a) highlights the importance of how all researchers interact theoretically through geopolitical and cultural borders. Using domain analysis, it is possible to assess what is actually important or significant in a scientific field, so that aspects such as trends, patterns, processes, dominant thoughts, agents and their relationships can be identified and analyzed. Thus, domain analysis becomes very important for research on knowledge organization, particularly regarding studies of epistemological configurations of the area and social processes that permeate the construction area, such as the production and scientific communication. This aspect will provide a contextual approach in accordance with the inherent values in their processes of the production and use of information (Guimarães 2015). It also facilitates theory building according to Hjørland and Albrechtsen (1995) and Smiraglia (2015).

Regarding the concept of domain, it can be understood as a field of study in its different specialties, a set of literature on a particular subject or group of people working together in an organization, comprehending the study of a discourse community and the role this community plays in science. A domain can be a scientific discipline, a scientific knowledge area or a discourse community related to a political party, religion or any other group. In this context, the notion of knowledge domain encompasses both the conceptual universe and the way that a given discourse community is formed (Hjørland and Albrechtsen 1995; Thellefsen and Thellefsen 2004; Mai 2005; Grácio and Oliveira 2013).

Domain analysis seeks the integration between individual and social context of the communities, where they are inserted and the concepts of information become meaningful when sharing occurs between these different communities and their members. It is an outstanding theoretical and methodological approach for the characterization and evaluation of science, typically represented by scientific literature or a research community, identifying the conditions under which scientific knowledge is constructed and socialized.

It is necessary to acknowledge the core and boundaries of certain knowledge to analyze a domain, regardless of its magnitude. In this sense, Tennis (2003) focuses his studies on domain, especially on methodological issues, rather than on conceptual issues, i.e., those operationalization procedures meant to define domains. His methodological conception seeks the construction of procedures for outlining definition of domains using two analytical devices he refers to as axes: "areas of modulation" set parameters and scope for a domain, and "degrees of specialization," which qualify and set the intension of a given domain. Although primarily applied to disciplinary domains, López-Huertas (2015) points to the need for and application of domain analysis to interdisciplinary environments if it is to be more broadly applicable to the study of research communities.

Through domain analysis, it becomes possible to verify what is actually significant in a particular area, such as trends, theoretical currents, patterns, processes, agents and relationships that can be identified and analyzed. In this context, an analysis and assessment of scientific production has become essential to create instruments for identifying a science's behavior. This highlights the role of bibliometrics to make a significant contribution by providing a quantitative analysis of the communication processes and of the nature and development of scientific domains that allows an objective and broad view of a scientific domain.

Among the methodologies for evaluation of science, bibliometrics stands out. Bibliometrics is defined by Broadus $(1987,376)$ as "the quantitative study of physical published units, or of bibliographic units, or of surrogates of either." For Hjørland and Albrechtsen (1995), bibliometrics is a research area that provides valuable information about a discipline, as well as the relationships among disciplines, revealing social patterns of scientific communication.

Hjørland (2002) points out that complementary empirical approaches such as bibliometric analysis, combined with other approaches, especially epistemological and historical approaches, provide a broader and deeper knowledge of the studied domain. As a domain analysis approach, bibliometric indicators, when combined with appropriate analytical routines, can contribute to the visualization of different aspects and characteristics of a domain, such as production indicators (language, the forms of communication and knowledge organization), citation indicators (relevance criteria, epistemic communities) and relational indicators (collaboration patterns, front of scientific research, epistemic communities).

Among bibliometric studies, Hjørland (2002) highlights the contribution of citation and co-citation analysis to visualize scientific knowledge areas. Citation and cocitation analysis are relevant procedures for analyzing interlocution among researchers and their role in different areas of knowledge, as they contribute to the visuali- 
zation of communicative and interactive process, as well as the underlying structure of a knowledge domain. The set of references of scientific papers can thus be analyzed as a reflection of a discourse community, so as to constitute a domain. Although bibliometrics has been recognized as an efficient approach associated to other theoretical approaches within information science, it has rarely been used as suggested by the analytical approach of domain analysis, i.e., by adopting a social perspective in the study of informational practices.

For Hjørland (2002), the best way to correctly analyze bibliometric indicators is by also using qualitative domain analysis approaches such as historical, epistemological and critical studies, i.e., a contextualization is required for the obtained bibliometric data. The contextual dynamics of science and the development of individuals and their social relations must be considered to obtain a better understanding of scientific information. With specific regard to scientific information and research, the output of these discursive communities culminates in generated and disseminated scientific production; it is an essential product for the further development of increasingly specialized knowledge.

Studies assessing discursive communities and their outputs are essential to the investigation of the different areas of knowledge, by making it possible to extract and analyze community members' patterns of behavior and scientific relationships. Therefore, through quantitative analysis techniques, which establish scientific indicators, it becomes possible to recognize the knowledge of the production profile in a given domain. Such indicators are extremely important as they represent a means of studying the whole dynamics of science in a particular domain of knowledge.

Production indicators are basically constituted by the statement of the actor publications (researcher, research group, institution or country) and are intended to reflect their impact on the scientific community to which they belong, giving visibility to those most productive and the most prominent themes of an area of knowledge, contributing to the visualization of different aspects and characteristics of a domain, in which case having as specific aspects of language, forms of communication and organization of knowledge.

A citation is an objective indicator of scientific communication of a given area, characterized by its social, historical and dynamic and its close dependence on the academic literature (Hjørland 2013), allowing the identification of groups of scientists and their publications (Glänzel 2003), in order to show the researchers with greatest impact in the area, highlighting its paradigms, methodological procedures and also the elite researchers, those responsible for the construction of new knowledge in the area.
Citations define the domain, according to Smiraglia (2011b). Thus, direct citation relationships (e.g., where author A cites author B) can map scientific communication and contribute to the understanding of a discursive community to identify researchers with great impact in the area. It provides visibility to the theoretical references that support the community as well as its concepts, objects and methods. Furthermore, it contributes to the building of a network of relationships and documents the communication and the relationships between researchers. Grácio and Oliveira (2013) furthermore conclude that citation studies contribute to the evaluation of the dialogue between researchers and their role in a scientific area, for the visualization of the communicative and interactive process and the underlying domain structure studied.

Bibliographic coupling analysis is characterized by indicators responsible for the quantification of a connection between two articles when they use one or more of the same references. For Kessler (1963), the reference set used by the authors in their research shows the intellectual environment in which they work, and if two items have similar references, there is an implicit relationship between them. The more references they share, the more similar the articles are thought to be. This, in essence, represents the bibliographic coupling hypothesis: "if two articles are referring to the same source, they exhibit theoretical and / or methodological proximity" (Kessler 1963, 11).

Author bibliographic coupling analysis, where author A cites one or more of the same references as author B, was introduced by Zhao and Strotmann (2008) to map the scientific activities of the authors and contribute to the achievement of a more realistic and detailed view of the intellectual structures of a scientific domain and to broaden the understanding of the analysis of citation networks based on authors. Zhao and Strotmann focus on the sources authors cite throughout their oeuvre, or body of work. By focusing on the cited references of authors, this can provide a more complete picture of the structure, characteristics and development of scientific knowledge of knowledge networks. They also represent how authors situate themselves within a domain by identifying the sources, and ultimately the authors, that have influenced their work. This idea of author bibliographic coupling analysis has been extended to other analysis units, such as co-word analysis by Yang et al. (2016), where the use of the same keywords that describe the content of articles is studied.

Small (1973) proposes that a co-citation relationship exists when two or more documents, authors or journals are cited together in a third subsequent paper, e.g., where author A and author B are cited in the same paper. The 
more frequently two entities are co-cited, the closer the relationship between them is believed to be. In this sense, authors that have been co-cited may present, at least from the perspective of the citing authors, similarity, complementarity, overlap or even opposing ideas, according to Grácio and Oliveira (2013).

For Small (2004), when scientists agree with what constitutes the relevant literature, including what is significant in that literature, they are actually defining the structures of their communities, and yet, "structure of science is generated by patterns of co-recognition" (Small 2004, 71). Thus, "when documents are co-cited, citing authors are awarding recognition as well as creating an association of meanings" (Small 2004, 76).

Finally, Hjørland (2002) confirms that the bibliometric approach-here used as direct citation, author bibliographic coupling and co-citation and analysis-provides many details and real connections between individual documents. These details and connections highlight the explicit recognition of the interdependence of the authors, through their articles, research, courses, theoretical and methodological approaches, etc. In order to interpret the results of bibliometric studies properly, one must know and employ the approaches of historical, epistemological and critical studies. Thus, it is necessary to contextualize the bibliometric data obtained, using the knowledge gained through domain analysis.

\subsection{Methodology}

We chose the journal Knowledge Organization in order to analyze the knowledge organization domain within information science. The journal is one of the few periodicals that focuses on the area of $\mathrm{KO}$, although research on $\mathrm{KO}$ may appear in other journals more sporadically.

The corpus for the analysis consisted of a total of 529 Knowledge Organization articles indexed in Clarivate Analytics' Web of Science ${ }^{\mathrm{TM}}$ database, over the period 19932016, when the journal adopted its current name. We limited the research corpus for this study to articles, which are considered not only the main vehicle for scientific communication among researchers but also are responsible for the dissemination of the results of research in a given area of knowledge. Peer reviewed articles also validate scientific knowledge. The full bibliographic record and cited references for each paper were downloaded in a tab-delimited format.

We conducted a domain analysis for knowledge organization, following a bibliometric approach, by analyzing indicators such as citations, co-citations and author bibliographic coupling. The data analyzed for these articles included the authors' references (excluding selfcitations) and keywords. The application VOSviewer, ver- sion 1.6.5 (Van Eck and Waltman, 2010), was used to visualize the author citation, co-citation and bibliographic coupling networks as distance-based graphs for which the relationships between nodes of analysis (i.e., authors) are represented through distance and the influence of individual nodes is represented by the node size. VOSviewer accepts Web of Science data file output directly so that the bibliographic relationships of interest do not need to be processed prior to loading into the software.

\subsection{Results}

Given the large number of authors (620 authors for the 529 papers), the analysis focused on the most prolific contributors to the journal, where different cutoff points were identified for the analysis to provide an indication of the relationships among the core contributors. Also, the resulting maps were more easily interpreted by focusing on the authors with the highest numbers of publications or citations in the respective maps.

The most productive authors who have published in Knowledge Organization appear in Table 1. Ten authors, each contributing at least six published articles, constitute the elite research contributors to the journal. As with class authority productivity research, the frequency distribution of authors and papers is highly skewed. Only forty authors contributed at least three articles to the journal, with the remaining 580 contributing one or two articles.

\begin{tabular}{|l|c|c|}
\hline Most productive authors & \# articles & \% \\
\hline HJORLAND B & 11 & 2.08 \\
\hline MARTINEZ-AVILA D & 9 & 1.70 \\
\hline TENNIS JT & 9 & 1.70 \\
\hline GNOLI C & 7 & 1.32 \\
\hline SATIJA MP & 7 & 1.32 \\
\hline SMIRAGLIA RP & 7 & 1.32 \\
\hline DAHLBERG I & 6 & 1.13 \\
\hline FOX MJ & 6 & 1.13 \\
\hline GUIMARAES JAC & 6 & 1.13 \\
\hline MAI JE & 6 & 1.13 \\
\hline
\end{tabular}

Table 1. Most productive authors in the journal Knowledge Organization (1993-2016).

From this summary, it is possible to observe the core of the most productive researchers contribute to areas of $\mathrm{KO}$ that the community recognizes as fundamental for the development of the domain, in topics such as classification, ethics, taxonomy and domain analysis. Produc- 
tivity represents one aspect of author contributions that can help to define the intellectual structure of a domain but does not necessarily reflect the influence of the authors.

Table 2 summarizes the most cited authors who have contributed at least two articles. Citation counts are based only on the references appearing in the 529 papers, which reflect how authors of $\mathrm{KO}$ cite each other. Although there is a strong correlation between the number of publications and the number of citations (Pearson's $r$ value of 0.733 , which is significant at the .01 level), higher publication counts do not necessarily result in higher citation counts. Also, an author such as Hartel, who contributed two articles during the study period, demonstrates that one does not need to be prolific to be influential. Her contributions have attracted the highest number of citations per article.

To complement the citation counts, a citation network was constructed in VOSviewer with the most productive authors and their theoretical references, shown in Figure 1. The map is limited to authors who have contributed at least four articles to the journal Knowledge Organization during the study period. The resulting relationships are based on the citer/citing behavior of the authors, where citing authors were influenced by the cited author. Note that the node size indicates the number of other authors in the network that have cited the given author.

The location of authors near the center of the map generally implies a more central role within the network. However, this does not indicate that authors on the periphery are less influential. Rather, within this community they tend not to cite many of the authors in the center of the network. Physical proximity also indicates a closer thematic relationship based on references made to each other. The work of Hjørland, Mai, Tennis and Albrechtsen demonstrate closer thematic ties due to their close proximity. A similar relationship can be seen with Fox, Kipp, Martinez-Avila and Olson, who are located in close proximity to one another. All four are, or were, located at the same institution and have co-authored. There are similar co-authorship or institutional relationships between several of the other authors such as Hjørland, Mai and Albrechtsen.

Figure 2 summarizes the author bibliographic coupling relationships between the twenty most productive authors for the study time period who have contributed a minimum of four articles (Note that one author with a total link strength of zero, i.e., no citation connection to the other authors, was removed). The bibliographic coupling relationship also reflects the author relationship strength from the authors' perspectives themselves based on the works they cite, but unlike the citer/citing relationship in Figure 1 above, this relationship is not limited to authors citing each other but rather how they cite the community of authors' works; so the analysis does not limit itself to productive authors within the journal. The resulting map produces two broad groupings of authors. The proximal relationships among the authors on the right side of the map are similar, but not precisely the same, as the relationship observed in Figure 1. In this case, Fox serves as a bridge between the two groups by citing works by authors in each group. Authors on the left side of the map tend to cite more of the same authors. Both the direct citation relationships based on author A citing author B and the broader relationship through author bibliographic coupling where authors A and B cite the same works, demonstrate similar proximity relationships for many of the authors appearing in both maps.

Whereas the citation and bibliographic coupling analysis show citer/cited relationships and highlight how authors themselves are influenced by other researchers based on citation practice, co-citation analysis highlights how members of the research community view the relationships among authors by citing their works together. The resulting co-citation network is shown in Figure 3. In-

\begin{tabular}{|l|c|c|c|c|}
\hline Most cited authors & \# citations & $\begin{array}{c}\mathbf{\%} \\
\text { citations }\end{array}$ & \# articles & Citations per Article \\
\hline HJORLAND B & 217 & 12.99 & 11 & 19.7 \\
\hline MAI JE & 58 & 3.47 & 6 & 9.7 \\
\hline TENNIS JT & 57 & 3.41 & 9 & 6.3 \\
\hline HARTEL J & 57 & 3.41 & 2 & 28.5 \\
\hline GNOLI C & 53 & 3.17 & 7 & 7.6 \\
\hline DAHLBERG I & 53 & 3.17 & 4 & 13.3 \\
\hline BEGHTOL C & 53 & 3.17 & 6 & 8.8 \\
\hline OLSON HA & 40 & 2.39 & 4 & 10.0 \\
\hline ALBRECHTSEN H & 37 & 2.21 & 4 & 9.3 \\
\hline
\end{tabular}

Table 2. Most cited authors in the journal Knowledge Organization (1993-2016). 


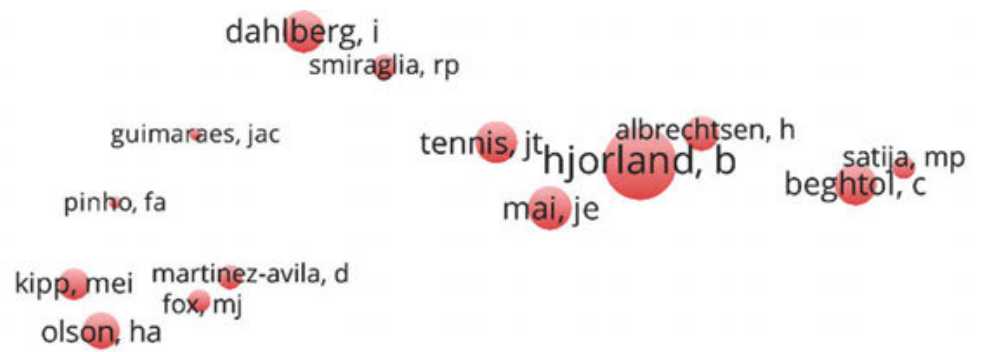

\section{VOSviewer}

Figure 1. Citation analysis of the most productive authors in the journal Knowledge Organization (1993-2016).

riggs, fw

guimaraes, jac pinho, fa

fox.mj

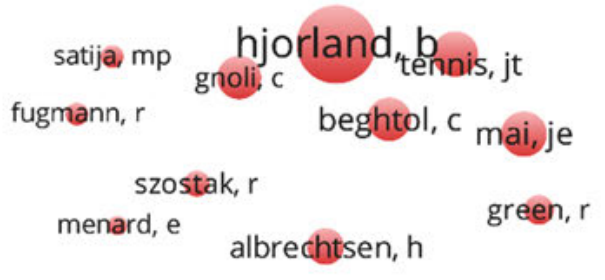

martinez-avila, $d$

olson ha kipp.mei

\section{is VOSviewer}

Figure 2. Author bibliographic coupling analysis of the most productive authors in the journal Knowledge Organization (1993-2016).

cluded authors received at least 200 citations, limited to those who appeared as the first authors of a given article. Authors with at least 30 citations were included, resulting in twenty-one authors appearing on the map.

The different perspective provided by co-citations still shows some similar relationships as observed with the direct citer/citing relationships. Hjørland continues to occupy a central role in the network, with close relationships with Beghtol and Tennis. A number of other authors not appearing on the most prolific or most cited list also appear on the map, indicating their relationships with the more prolific authors, even if they themselves have not published extensively in $\mathrm{KO}$ or have been widely cited. Researchers such as Svenonius, Soergel, Wittgenstein, Bowker and Frohmann, although not appearing on the most prolific or most cited individual author lists, still demonstrate a research connection to the more prolific authors by being co-cited with them. Olson's research, for example, has contributed to multiple areas such as subject representation and classification, inter-indexer consistency, feminist perspectives and research methods (Wolfram 2016), and her works are used by the many research- 


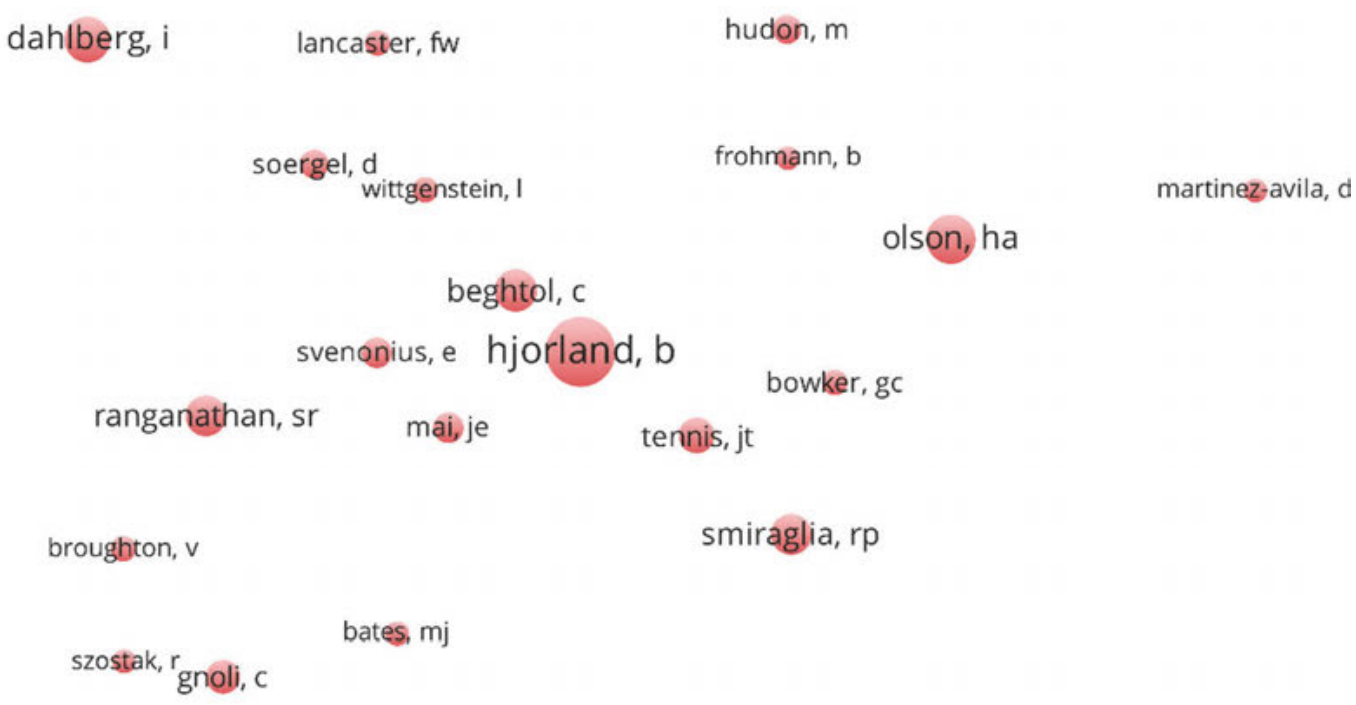

\section{VOSviewer}

Figure 3. Co-citation network among the theoretical references of the most productive authors in the journal Knowledge Organization (19932016).

ers in the area. One could expect highly cited authors to appear in closer proximity to one another simply due to the fact that they have more citations that could co-occur. Although this may be true for some pairs of authors, it is not always the case.

\subsection{Discussion}

An exploration of authors individually within a given domain can be descriptive of the authors themselves but is not very revealing about the intellectual structure of the domain. By examining the network of citation relationships through direct citation, bibliographic coupling and co-citation, we can provide a greater understanding of how researchers influence one another and how they are situated within the field by their peers. Citation-based analyses favor authors with established records who have had greater time to publish and to accrue more citations to their work. The most productive and influential authors of the journal (Hjørland, Tennis, Gnoli, Dahlberg and Mai), for the most part, were those with a longer history of publication in the field. This is also reflected in the significant positive correlation between productivity and citations observed for the most prolific authors. The most prolific and cited author, Hjørland, was situated centrally in each map. His work has dealt with fundamen- tal issues of $\mathrm{KO}$ and his central proximity to many other authors demonstrates his influence on the research community.

How authors situate themselves within the research community through their citing other authors, as reflected in the citation and author bibliographic coupling maps, provides one vantage point of the research community. There is a consistent core of theoretical references among the most productive authors. The active cross-citation among the authors cited in this core indicates the actual role of the journal Knowledge Organization as a space for knowledge construction in the area of knowledge organization. The citation and bibliographic coupling maps were complementary in demonstrating the intellectual proximity of authors to one another, with the closest relationships among Hjørland, Tennis, Gnoli and Beghtol. The theoretical proximity between Guimaraes and Pinho, as well as between Martinez-Avila, Olson and Kipp highlight the similarity in their references. This is also undoubtedly due in part to each of them having worked together as part of the same research group, which resulted in the production of articles with similar themes such as classification, ethical and epistemological studies.

The intellectual proximity of the authors on the maps can also be influenced by the geographic proximity of 
the authors. Authors from the Americas are situated on the right side of the map in Figure 2 and most of the authors on the left side, with some exceptions, are European authors. Closer geographic proximity can contribute to mutual awareness of one another's research or can promote co-authorship. Katz (1994), for example, noted that collaboration decreased with increasing geographic distance within countries but did not necessarily dissuade international collaboration. We see this in the closer proximity in Figure 1 of Hjørland, Albrechtsen and Mai, and Olson, Fox, Kipp and Martinez-Avila who are/were colleagues at the same institution. However, geography should be considered a secondary influencing factor than other more prominent factors such as collaboration, mutual interest or access to relevant literature. Several North American scholars (e.g., Beghtol, Smiraglia, Menard, Szostak, Green) are more closely aligned with European scholars based on their citing activity and may be more closely aligned to researchers at other institutions.

Co-citation analysis, conversely, provides an indication of research relatedness as perceived by members of the research community itself in the way authors and their works are cited. In addition to Hjørland, other influential authors based the strength and number of connections to other authors included Olson and Dahlberg. Although these three authors are not very closely situated to one another, they represent more prominent nodes in the network. All three examine fundamental issues of the discipline, such as classification, and have written.

The present research has demonstrated how bibliometric methods based on citation data can serve as a valuable tool for domain analysis when combined with more qualitative analytical methods. We must acknowledge several limitations of the research. First, the focus on a single journal, Knowledge Organization, although central to the domain of $\mathrm{KO}$ itself, does not represent the entire population of $\mathrm{KO}$ research. How the authors investigated here represent their research identity through referencing behavior in other publication venues may be different. Second, the co-citation analysis map was limited to co-citations between first authors of publications. If publications had more than one author, the cocitations with the non-lead authors were not recorded by VOSviewer, thereby limiting the connections with these other authors. Third, there are different visualization approaches based on network characteristics and proximity analysis that may be used to study scholarly networks. Different tools may rely on different methods to represent these relationships. Although the outcomes of the analyses may not provide definitive proof of believed relationships within domains, they provide evidence to support the interpretation of the complex web of relationships that exist within domains.

\subsection{Conclusion}

The journal Knowledge Organization provides a window into $\mathrm{KO}$ research topics and interactions among KO contributing researchers. The journal's focus on all aspects of $\mathrm{KO}$ provides an important venue for the international $\mathrm{KO}$ research community to share research developments and, in turn, to be influenced by others' work. The analysis of the most productive authors and their theoretical commonalities through citation, co-citation and author bibliographic coupling and, jointly with effective approaches to the visualization, along with a more qualitative understanding of the scientific domain analyzed, specifically as it relates to the social dynamics of scientific communication processes.

The present study represents a relatively small scale exploration of a single domain as reflected in the literature of a key publication venue for the domain of $\mathrm{KO}$. Analysis at the journal level, particularly for a journal with a well-defined disciplinary scope, represents a convenient demarcation for studying the discipline. Future research may examine expanded data sets that encompass larger numbers of core publication venues focused on the domain. This, in turn, can lead to an examination of the boundaries and relationships of different domains with KO based on citation practices to more fully identify the boundaries of the field.

\section{References}

Arboit, Aline Elis, Ely Francina Tannuri de Oliveira, Leilah Santiago Bufrem and Rene Faustino Gabriel Junior. 2015. "O modelo científico no domínio de organização do conhecimento: Um estudo a partir dos trabalhos apresentados nos congressos internacionais da ISKO.” In II Congreso ISKO España-Portugal XII Congreso ISKO España: Organización del conocimiento; Sistemas de información abiertos; Actas, ed. José Vicente Rodríguez Muñoz, Isidoro Gil Leiva, Pedro Manuel Díaz Ortuño, and Francisco Javier Martinez Méndez. Murcia, Universidad de Murcia. http://www.iskoiberico.org/wpcontent/uploads/2015/11/70_Arboit.pdf

Broadus, Robert N. 1987. "Early Approaches to Bibliometrics." Journal of the American Society for Information Science 38: 127-9.

Glänzel, Wolfgang. 2003. "Bibliometric as a Research Field: A Course on Theory and Application of Bibliometric Indicators.” National Science Digital Library. http://nsdl.niscair.res.in/jspui/handle/123456789/ 968

Grácio, Maria Cabrini Grácio and Ely Francina Tannuri de Oliveira. 2013. "Análise de cocitação de autores: um estudo teórico-metodológico dos indicadores de prox- 
imidade, aplicados ao GT7 da ANCIB." LiiNC em Revista 9: 196-213.

Guimarães, José Augusto Chaves. 2008. "Ciência da informação, arquivologia e biblioteconomia: em busca do necessário diálogo entre o universo teórico e os fazeres profissionais." In Ensino e pesquisa em biblioteconomia no Brasil: A emergência de um novo olhar. organizadores José Augusto Chaves Guimarães and Mariângela Spotti Lopes Fujita. São Paulo: Cultura Acadêmica, 33-44.

Guimarães, José Augusto Chaves. 2015. “Análise de domínio como perspectiva metodológica em organização da informação." Ciência da informação 43, no. 1. http:/ / revista.ibict.br/ciinf/article/view/1415/1593

Hjørland, Birger. 2002. "Domain Analysis in Information Science: Eleven Approaches Traditional as Well As Innovative." Journal of Documentation 58: 422-62.

Hjørland, Birger. 2008. "What is Knowledge Organization (KO)?” Knowledge Organization 35: 86-101.

Hjørland, Birger. 2013. "Citation Analysis: A Social and Dynamic Approach to Knowledge Organization.” Information Processing \& Management 49: 1313-25.

Hjorland, Birger and Hanne Albrechtsen. 1995. "Toward a New Horizon in Information Science: DomainAnalysis." Journal of the American Society for Information Science 46: 400-25.

Katz, J.S. 1994. "Geographical Proximity and Scientific Collaboration." Scientometrics 31: 31-43.

Kessler, M. M. 1963. "Bibliographic Coupling Between Scientific Papers." American Documentation 14: 10-25.

López-Huertas, María J. 2015. "Domain Analysis for Interdisciplinary Knowledge Domains." Knowledge Organization 42: 570-80.

Mai, Jens-Erik 2005. "Analysis in Indexing: Document and Domain Centered Approaches." Information Processing \& Management 41: 599-611.

Small, Henry. 1973. "Co-citation in the Scientific Literature: A New Measure of the Relationship Between Two Documents." Journal of the American Society for Information Science 24: 265-69.

Small, Henry. 2004. "On the Shoulders of Robert Merton: Towards a Normative Theory of Citation." Scientometrics 60: 71-9.
Smiraglia, Richard P. 2011a. "Domain Coherence within Knowledge Organization: People, Interacting Theoretically, Across Geopolitical and Cultural Boundaries." In Exploring Interactions of People, Places and Information: Les intersections; Gens, lieux, information: Proceedings of the Annual Conference of CAIS, University of New Brunswick/St. Thomas University, Fredericton, N.B. Canada, June 2 - 4, 2011, ed. Pam McKenzie, Catherine Johnson, and Sarah Stevenson. https://journals.library. ualberta.ca/ojs.cais-acsi.ca/index.php/cais-asci/ article/view/601/551

Smiraglia, Richard P. 2011b. "ISKO 11's Diverse Bookshelf: An Editorial.” Knowledge Organization 38: 179-86.

Smiraglia, Richard P. 2014. "The Epistemological Dimension of Knowledge Organization." IRIS-revista de informação, memória e tecnologia 2: 2-11. https://periodicos. ufpe.br/revistas/IRIS/article/view/498/402

Smiraglia, Richard P. 2015. Domain Analysis for Knowledge Organization: Tools for Ontology Extraction. Chandos Information Professional Series. Waltham, MA: Chandos Publishing.

Tennis, Joseph T. 2003. “Two Axes of Domains for Domain Analysis.” Knowledge Organization 30: 191-5.

Thellefsen, Torkild L. and Martin M. Thellefsen. 2004. "Pragmatic Semiotics and Knowledge Organization." Knowledge Organization 31: 177-87.

Van Eck, Nees Jan and Ludo Waltman. 2010. "Software Survey: VOSviewer, a Computer Program for Bibliometric Mapping."' Scientometrics 84: 523-38.

Wolfram, Dietmar 2016. "The Power to Influence: An Informetric Analysis of the Works of Hope Olson." Knowledge Organization 43: 331-7.

Yang, Siluo, Ruizhen Han, Dietmar Wolfram and Yuehua Zhao. 2016. "Visualizing the Intellectual Structure of Information Science (2006-2015): Introducing Author Keyword Coupling Analysis." Journal of Informetrics 10: 132-50.

Zhao, Dangzhi and Andreas Strotmann. 2008. "Evolution of Research Activities and Intellectual Influences in Information Science 1996-2005: Introducing Author Bibliographic-Coupling Analysis." Journal of the American Society for Information Science and Technology 59: 2070-86. 